\title{
Efficacy of airway pressure release ventilation for acute respiratory distress syndrome: A meta-analysis
}

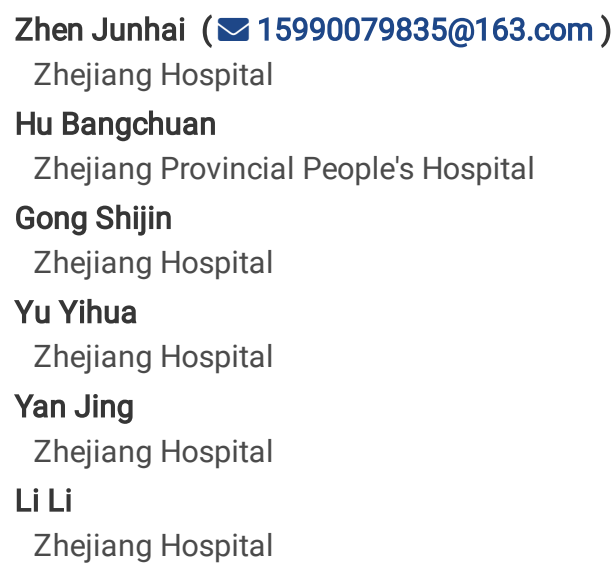

Keywords: Airway pressure release ventilation, Acute respiratory distress syndrome, Meta-analysis, Critically ill patients, Randomized control trials

Posted Date: December 11th, 2020

DOI: https://doi.org/10.21203/rs.3.rs-125434/v1

License: (a) (1) This work is licensed under a Creative Commons Attribution 4.0 International License. Read Full License 


\section{Abstract \\ Background}

Airway pressure release ventilation (APRV) has been described many years, however, it is still unclear whether APRV improves outcomes in critically ill patients admitted to Intensive Care Unit with acute respiratory distress syndrome (ARDS).

\section{Methods}

3 databases were searched for randomized controlled trials (RCTs) until 8 August 2019. The relative risk (RR), mean difference (MD) and 95\% confidence intervals $(\mathrm{Cl})$ were determined.

\section{Results}

A total of six randomized controlled trials (RCTs) were included with 360 ARDS patients. The Meta analysis showed that the mean arterial pressure (MAP) in APRV group is higher than traditional mechanical ventilation group $[\mathrm{MD}=2.35,95 \% \mathrm{Cl}=(1.05,3.64), P=0.0004]$, and the airway peak pressure (Ppeak) is lower in APRV group with statistical difference [MD=-2.04,95\% $\mathrm{Cl}=(-3.33,-0.75), P=0.002]$. However, no significant beneficial effect on oxygen index $\left(\mathrm{PaO}_{2} / \mathrm{FiO}_{2}\right)$ was shown between two groups $(\mathrm{MD}=26.24,95 \% \mathrm{Cl}=(-26.50,78.97), P=0.33)$. Compared with conventional mechanical ventilation, APRV significantly improved 28-day mortality $[\mathrm{RR}=0.66,95 \% \mathrm{Cl}=(0.47,0.94), P=0.02]$.

\section{Conclusions}

For critically ill patients with ARDS, application of APRV is associated with the increase of MAP, the reduction of the airway Ppeak and 28-day mortality, while there is no sufficient evidence to support the $\mathrm{APRV}$ is superior to conventional mechanical ventilation in $\mathrm{PaO}_{2} / \mathrm{FiO}_{2}$.

\section{Introduction}

Acute respiratory distress syndrome (ARDS) is a common cause of acute respiratory failure in intensive care unit (ICU). ARDS is characterized by pulmonary edema, hyaline membrane formation and atelectasis with progressive respiratory distress and refractory hypoxemia. Mechanical ventilation has been applied in critically ill patients with ARDS for a long time to promote lung recruitment, improve lung compliance, and therefore improve the lung ventilation and gas exchange. Mechanical ventilation strategies, such as low tidal volume ventilation (LTV), positive end expiratory pressure (PEEP), permissive hypercapnia ventilation (PHV), and high frequency oscillatory ventilation (HFOV) had been applied to ARDS. Unfortunately, up to now the mortality of ARDS is still as high as $40 \%{ }^{[1]}$. Therefore, it is imperative that we seek an effective mode of mechanical ventilation for the management of ARDS.

Airway pressure release ventilation (APRV) has been described for more than 30 years. In 1987, Downs ${ }^{[2]}$ et a/ firstly proposed the conception of APRV. APRV is essentially a pressure control mode which is adjusted by setting different levels of pressure. First set a high airway pressure ( $P$ high) before starting ventilation, triggering controlled ventilation when the high airway pressure is briefly and quickly released to another lower level (usually $0 \mathrm{~cm} \mathrm{H} \mathrm{H}_{2} \mathrm{O}, \mathrm{P}$ low), which allows the lungs partial contraction, and then quickly return to high airway pressure before unstable alveolar collapse. APRV can prevent further collapse of unstable alveolar units, and can also cause alveolar recruitment in damaged lung tissue. Reports showed that APRV had lower airway peak pressure (P peak) and mean pressure than traditional mechanical ventilation modes $^{[3]}$. Also, APRV can benefit physiologically, improving clinical outcomes such as hemodynamic changes and respiratory dynamics.

Recently, Han ${ }^{[4]}$ et al. found APRV effectively improved oxygenation and kept hemodynamic stability when compared with LTV in canines with ARDS. In clinical practice, there were also evidences revealed its advantage in improving oxygen, reducing the impact on circulation and the mortality compared with other modes of mechanical ventilation ${ }^{[5,6]}$, However, Maxwell RA ${ }^{[7]}$ et al. found that there is no statistical difference between APRV and other ventilation modes as for ventilator days, length of stay, ventilator-associated pneumonia, mortality in adult trauma patients. Therefore, it is still a controversy whether APRV is more effective than traditional mechanical ventilation modes. Recently, several randomized controlled trials (RCTs) were published investigating the effect of APRV for mechanical ventilation in critically ill patients with ARDS. we make an unified standard to systematically analyze the results provided by these trials.

\section{Materials And Methods}

\subsection{Literature search strategy}


According to the criteria of literature inclusion and exclusion, two researchers sifted the literatures of Pubmed, Cochrane, Embase databases independently. The retrieval time was from the establishment of the library to 8 August 2019. Languages were not restricted. The search was performed using the following items: airway pressure release ventilation/APRV, acute respiratory distress syndrome/acute lung injury/ARDS/shock Lung, randomized controlled trials/RCT. Disagreements of study research were resolved by discussions, when discussions failed to solved the disagreements, a third author was involved to make decision.

\subsection{Inclusion criteria}

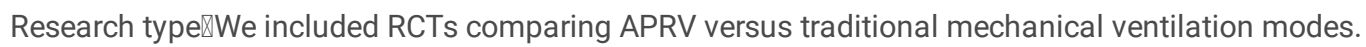

Study participants: Critically ill patients aged 18 years and older with ARDS in an ICU setting met the Berlin criteria for ARDS published in 2012 by the Council of the European Society of critical care medicine and the American Thoracic Society (ATS).

Intervention measures: Patients in APRV group received APRV as mechanical ventilation strategy. Participants in the control intervention group were those who received traditional mechanical ventilation modes including synchronized intermittent mandatory ventilation (SIMV), LTV, Control mechanical ventilation (CMV) and assistant/control mode (A/C). Mechanical ventilation modes in two groups did not overlap and all were parallel control trials.

Outcome measures: 28-day Mortality, Oxygenation index $\left(\mathrm{PaO}_{2} / \mathrm{FiO}_{2}\right)(\mathrm{mmHg})$, mean arterial pressure (MAP), airway peak pressure ( $\mathrm{P}$ peak).

\subsection{Exclusion criteria:}

Exclusion of Observational studies, quasi-randomized or crossover studies, case reports, animal studies, pediatric population, review articles and repeated reports.

\subsection{Data extraction}

Two researchers independently extracted data according to the inclusion and exclusion criteria. Disagreements were solved by discussion, when discussion failed to solved the disagreements, we asked for a third author to discussion and consensus. We used self-made data extraction table to extract data, the extracted contents include (1) Basic information of studies: the authors' name, publication time, counties; (2) Participants of studies: sample size, sex, age; (3) Intervention measures: the kinds of the mechanical ventilation modes; (4) Research results: 28-day Mortality, $\mathrm{PaO}_{2} / \mathrm{FiO}_{2}$, MAP, airway $\mathrm{P}$ peak.

\subsection{Methodological quality assessment}

The assessment of the risk bias was conducted following to the Cochrane Handbook for Systematic Reviews of Interventions, including the following 7 aspects: random sequence generation, allocation concealment, blinding of patients and personnel, blinding of outcome assessment, incomplete outcome data, selective reporting and other sources of bias. The assessment criteria were as follows, high risk bias: any aspect above be regarded as high risk. Low risk bias: all the aspects were low risk. Unclear risk bias: unclear risk in any aspects whiles no high bias in other aspects.

\subsection{Statistical method}

Studies were collated and checked according to the requirements of meta-analysis. Data analysis was performed by using ReviewManager 5.3 software provided by the Cochrane international cooperation organization. Using two-sided test, the level of significance was 0.05 , $P<0.05$ in two-sided tests was considered as statistically significant. Metrological data (Ppeak, MAP, PaO2/FiO2) was analyzed with mean deviation (MD) and standard deviation (SD), and counting data (28-day mortality) was analyzed with relative risk (RR) and 95\% confidence intervals $(95 \% \mathrm{Cl})$ as effect statistic. If the study had no significant heterogeneity $\left(I^{2}<50 \%, P>0.05\right)$, we use the Peto Mantel-Haenszel fixed effect model. If significant $\left(I^{2}>=50 \%, P<0.05\right)$, we use the Dersimonian Laird random effect model. Reverse funnel plots were used to analyze potential publication bias. If appropriate, we will perform sensitivity analysis to assess the review results.

\section{Results}

\subsection{The results of literature retrieval}

A total of 367 articles were searched, 224 in Pubmed; Embase,120 citations; Cochrane databases and other sources (such as abstracts from conferences), 16 and 7 citations respectively. There were 197 articles left after removing the reduplicated articles. After reading the abstracts, some articles were excluded for they belong to observational studies, case reports, animal studies, pediatric population, review articles and 
repeated reports reviews. There were 8 articles remained, then we read the full text of the 8 studies in detail, 2 studies were removed for lacking relevant outcome indications or too short observation time. Finally, 6 studies were included. (Fig.1)

\subsection{Basic information of RCTs included}

The key baseline characteristics are illustrated in Table 1. The publication time of studies ranged from Jan. 2003 to Dec. 2017 , the trials all were parallel control trials. The studies' population included Asian, European and American. The outcome indications included 28-day Mortality, $\mathrm{PaO}_{2} / \mathrm{FiO}_{2}$, MAP, airway $\mathrm{P}$ peak. A total of 360 patients were included with 172 patients in APRV group and 188 patients in control group. The sample size ranged from 22-138. The age of patients was between 30-80 years. Details of the baseline characteristics of study participants were shown in Table 2.

\subsection{Results of methodological quality evaluation}

After the methodological quality assessment of 6 included studies, no study was judged to be at low risk of bias or regarded to be high risk bias, All studies belonged to unclear risk of bias. (detailed in Fig.2).

\subsubsection{Results of meta-analysis}

\subsubsection{MAP}

There were 4 studies included ${ }^{[1,5,8,9]}, 137$ patients in APRV group, 162 in control group, no statistical heterogeneity between two groups $\left(P=0.41 \mathrm{I}^{2}=0\right)$. We used Peto Mantel-Haenszel fixed effect model, the result showed there was statistical difference for MAP $(\mathrm{MD}=2.35,95 \% \mathrm{Cl}=$ (1.05,3.64), $P=0.0004)$. (Fig.3) APRV group had higher MAP compared with control group.

\subsection{2 $\mathrm{PaO} 2 / \mathrm{FiO} 2$}

There were 5 RCTs included ${ }^{[1,5,8-10]}, 154$ patients in APRV group, 173 in control group. There is statistical heterogeneity between two groups $\left(P<0.00001 \mathrm{I}^{2}=93 \%\right)$. Thus, we used dersimonian laird random effect model. The result showed no statistical difference for $\mathrm{PaO}_{2} / \mathrm{FiO}_{2}$ between two groups (MD=26.24, 95\% $\mathrm{Cl}=(-26.50-78.97), P=0.19)$ (Fig.4) .

\subsubsection{Airway Ppeak}

There were only 2 studies included ${ }^{[1,8]}, 97$ patients in APRV group and 93 in control group. Because statistical heterogeneity was shown between two groups $\left(P=0.39 \mathrm{I}^{2}=0\right)$, we used Peto Mantel-Haenszel fixed effect model. The result showed there was statistical difference for airway Ppeak (MD=-2.04, 95\% $\mathrm{Cl}=(-3.33,-0.75), P=0.88)$ (Fig.5) between two groups.

\subsubsection{8-day mortality}

In terms of the 28-day mortality, 5 RCTs were included [1, 6, 8-10], there were 162 patients in APRV group and 176 patients in control group. We used fixed effect model because of no statistical heterogeneity $\left(P=0.82 \mathrm{I}^{2}=0\right)$, there was significantly statistical difference between 2 groups for 28-day mortality $(\mathrm{RR}=0.66,95 \% \mathrm{Cl}=(0.47,0.94), P=0.02)$ (Fig.6). The odds of mortality of patients with ARDS and application of APRV were $34 \%$ lower than control group.

\subsection{Sensitivity and publication bias analysis}

We can easily notice the heterogeneity between two groups from fig. $4\left(P<0.00001, I^{2}=93 \%\right)$, In order to find the potential sources of heterogeneity, we carried out leave-one-out sensitivity analysis $₫$ and the removal of any study failed to reduce the value of $\mathrm{I}^{2}$ below $50 \%$. We believe that the heterogeneity didn't derive from a particular study included. From table 1, there was a significant difference in the sample size of each study, from 22 to 138 . Moreover, the baseline of $\mathrm{PaO}_{2} / \mathrm{FiO}_{2}$ varied among different studies, especially in the study from Ota, $\mathrm{K}^{[10]}$ et al, which may be one of the causes of heterogeneity. We also assessed the publication bias through funnel plot for $\mathrm{PaO}_{2} / \mathrm{FiO}{ }_{2}$, we chose $\mathrm{RR}$ value as the horizontal abscissa, while the SE (Standard Error) value as the ordinate, for the funnel plot was not symmetrical visually, suggesting the possibility of publication bias (Fig.7).

\section{Discussion}

Our systematic review was concentrating on the effect of APRV on the critically ill patients with ARDS. 6 RCTs were identified, altogether 360 patients were included in this meta-analysis. The major finding of our review is that the application of APRV reduces airway P peak and has less impact on patients' circulation (APRV group had higher MAP) with lower 28-day mortality in critically ill patients with ARDS. 
For traditional mechanical ventilation modes, we usually set respiratory rate, pressure level, tidal volume, PEEP and other necessary parameters. Different to traditional mechanical ventilation modes, APRV is a special pressure limited, time switched biphasic positive airway pressure (BIPAP) ventilation mode. In its parameter setting, we need set high airway pressure levels (Phigh; 20-35 cmH20, generally less than $35 \mathrm{cmH} 20$ ) and it's time (Thigh; 4-6 seconds), low airway pressure levels (Plow; generally 0 ) and it's time (Tlow ; Defined as the time when expiratory flow rate decreases to $75 \%$ of the peak expiratory flow rate) ${ }^{[11]}$. However, there is still a lack of consistency on how APRV is applied internationally.

Theoretically, APRV is useful in promoting recruitment of lung and maintaining open of alveolar for its thigh is longer than Tlow. The concentration of surfactant proteins A and B in alveolar could be effectively preserved in APRV group at the early stage of ARDS/ALI animal models compared with other modes ${ }^{[12,13]}$. Yoshida ${ }^{[14]}$ et al. verified APRV was more efficient than pressure support ventilation (PSV) to decrease atelectasis in ARDS patients through analysis of 3-dimensional reconstruction, and volumetry of CT data. However, whether APRV is turely more effective in improving oxygenation than other modes is still under controversy for the results varied from different studies, some researchers found no significant difference in oxygenation between APRV and other modes ${ }^{[1,5,9]}$, while in 2017, the largest study assessed the efficacy of APRV in ARDS patients published up to now indicated APRV improved oxygenation(PaO2/FiO2) and respiratory system compliance compared with LTV ${ }^{[8]}$. Our meta-analysis didn't show higher PaO2/FiO2 in APRV group, on the one hand, the heterogeneity between two groups may influence the specific result of the meta analysis, on the other hand, the number of RCTs nowadays to assess effect of APRV in patients' oxygenation is small, no multicenter RCT was found in this filed, thus, it is necessary to conduct higher quality and larger sample size studies to further clarify the real effect of APRV in oxygenation among ARDS patients. It is noteworthy that though our study didn't show the advantage of APRV in oxygenation over traditional mechanical ventilation modes, lower 28-day mortality in APRV group was found, the reasons maybe as follow, firstly, our study didn't show APRV group had worser oxygenation than other modes, secondly, our meta-analysis demonstrated the better circulatory status (higher MAP) in APRV group, lastly, APRV may have other strengths like ameliorating inflammatory condition (see below) to improve 28-day mortality in ARDS patients.

In addition to the effect of APRV on respiratoy system, we also assessed the influence of APRV on patients' circulatory system, our metaanalysis showed the lower airway Ppeak in APRV group, which reduce the effect on circulation and decrease the incidence of pulmonary barometric injury ${ }^{[15]}$, Kapian L ${ }^{[16]}$ et al. found the lower Ppeak with APRV lead to decreased transmitted intrathoracic pressure, the reduced intrathoracic pressure enhances venous return, and therefore increased cardiac index (CI), with a decreased pressor requirement to support MAP and oxygen delivery when compared with Pressure controlled ventilation (PCV). Other experiments showed that APRV also increased the blood flow of organs such as liver ${ }^{[17]}$ kidney $^{[18]}$, thus improving the perfusion of those organs. In our study, APRV group had higher MAP further indicated the less side-effects on the circulatory function compared with traditional modes.

APRV also has other advantages when applied to ARDS. During APRV, ARDS patients maintain their own breath, this reduces the requirements of sedation and neuromuscular blocker, Habashi's study confirmed this ${ }^{[19]}$, moreover, Spontaneous breathing increases the blood flow of respiratory muscles and prevents the occurrence of respiratory muscle atrophy ${ }^{[20]}$. Different from other mechanical ventilation modes, ARDS transforms airway pressure to a lower level (Plow) for a short time regularly, during this release stage, Carbon dioxide will be eliminated effectively ${ }^{[11]}$. Surprisingly, some researchers even found ARDS may Inhibit the production of inflammatory factors, the apoptosis of endothelial cell, and the destruction of extracellular matrix (ECM) mediated by matrix metalloproteinase (MMP), and reduce the mortality of experimental animals ${ }^{[21]}$.

Bajaj, $A^{[22]}$ et al. had conducted a Meta analysis assessed the efficacy of APRV in critically ill patients compared with traditional ventilation modes in 2015, there was no significant difference in 28-day mortality of two groups $(\mathrm{OR}=0.74,95 \% \mathrm{Cl}=0.38 \sim 1.47 \mathrm{P}=0.40)$, Subgroup analysis performed on ALI/ARDS patients (3 studies) also revealed no significant difference in mortality at 28 days $(\mathrm{OR}=0.72,95 \% \mathrm{Cl}=0.32 \sim$ $1.60, P=0.42$ ), and the total number of patients was only 249 , the insufficient number of studies included in this meta analysis may influence the reliability of their result, although our findings about mortality are different to Bajaj, A's study, a strength of our analysis is that we included the newly published RCTs especially those published in the last 2 years, and more high-level evidence-based medical researches were included after strict screening, we concluded that APRV may reduce the mortality of critically ill patients with ARDS. In the systematic review of Penny $\mathrm{L}^{[23]}$ et al., Early application of APRV in traumatic patients represented lower mean ARDS incidence (14.0\% vs. $\left.1.3 \%\right)$ and in-hospital mortality (14.1\% vs. 3.9\%) compared with traditional mechanical ventilation modes, Unfortunately, all the studies involved were retrospective or observational. In the review of Jain.S. ${ }^{[24]}$ et al., they summarized the APRV in past 30 years, and thought APRV stabilizes alveoli and reduces the incidence of ARDS in clinically relevant animal models and in trauma patients, they regarded APRV as a highly lung-protective ventilation strategy.

Our meta-analysis has the following strengths. 2 researchers independently screened 3 databases and carefully evaluated the quality of each RCTs. (2) we used Cochrane risk of bias tool to assess the methodological quality. (3) To date, this is the largest meta-analysis conducted on 
the clinical effect of APRV in ARDS patients. (4) This is the first meta-analysis evaluated the efficiency of $\mathrm{APRV}$ in $\mathrm{MAP} \mathrm{PaO}_{2} / \mathrm{FiO} \mathrm{O}_{2}$ and airway P peak among ARDS patients.

There are still some shortcomings in this study: (1) most of the researches' sample size is small. (2) most trials are not blinded and may be biased. (3) in the meta analysis of $\mathrm{PaO}_{2} / \mathrm{FiO}_{2}$, the heterogeneity among the studies is large with publication bias. These defects may have impact on outcomes, therefore, it still needs to be cautious when reference to results of this study and must take the actual situation of the patients into consideration.

\section{Conclusions}

To summarize, A meta analysis of the literature included 6 RCTs evaluated the use of APRV compared with traditional mechanical ventilation modes for ARDS patients. Our study is strengthened by the addition of 3 recently published RCTs, Based on our study, this systematic review indicates that: APRV is more effective in reducing airway Ppeak, producing less impact on circulation (higher MAP),and improving 28-day mortality, while no therapeutic benefit in PaO2/FiO2 was found compared with traditional modes in critically ill patients with ARDS. For the number of included studies is still insufficient, more higher quality RCTs should be conducted to further clarify the real clinical effect of APRV in the treatment of ARDS in the future.

\section{Abbreviations}

RCTs randomized controlled trials; APRV airway pressure release ventilation; ARDS acute respiratory distress syndrome; ICU Intensive Care Unit; MAP mean arterial pressure; Ppeak airway peak pressure; LTV low tidal volume ventilation; PEEP positive end expiratory pressure; PHV permissive hypercapnia ventilation; HFOV high frequency oscillatory ventilation; SIMV synchronized intermittent mandatory ventilation; CMV Control mechanical ventilation; A/C assistant/control mode; RR relative risk; Cl confidence interval; MD mean difference; IQR interquartile rang; SD standard deviation.

\section{Declarations}

1.Ethics approval and consent to participate囚Not applicable.

2.Consent for publication $₫$ Not applicable.

3.Availability of data and materials $₫ \mathrm{D}$ ata sharing is not applicable to this article as this study is a meta analysis.

4.Competing interests $₫$ The authors declare that they have no competing interests.

5.Funding $\triangle T$ This work was supported by Zhejiang Provincial Program for the Zhejiang Medical and Health Science and Technology Program(2021450592).

6.Authors' contributions:(1) LL carried out the concept or design. (2) ZJ carried out the acquisition of data. (3) HB carried out the analysis or interpretation of data. (4) GS and ZJ carried out the drafting of the manuscript. (5) YY and YJ carried out the critical revision for important intellectual content. All authors read and approved the final manuscript.

7.Acknowledgements:Not applicable.

\section{References}

[1] LI J Q, LI N, HAN G J, et al. Clinical research about airway pressure release ventilation for moderate to severe acute respiratory distress syndrome [J]. European review for medical and pharmacological sciences, 2016, 20(12): 2634-41.

[2] STOCK M C, DOWNS J B, FROLICHER D A. Airway pressure release ventilation [J]. Critical care medicine, 1987, 15(5): 462-6.

[3] KAPLAN L J, BAILEY H, FORMOSA V. Airway pressure release ventilation increases cardiac performance in patients with acute lung injury/adult respiratory distress syndrome [J]. Critical care (London, England), 2001, 5(4): 221-6.

[4] HAN G J, LI J Q, PAN C G, et al. Experimental study of airway pressure release ventilation in the treatment of acute respiratory distress syndrome [J]. Experimental and therapeutic medicine, 2017, 14(3): 1941-6.

[5] SONG S, TIAN H, YANG X, et al. [The clinical effect of airway pressure release ventilation for acute lung injury/acute respiratory distress syndrome] [J]. Zhonghua wei zhong bing ji jiu yi xue, 2016, 28(1): 15-21. 
[6] VARPULA T, JOUSELA I, NIEMI R, et al. Combined effects of prone positioning and airway pressure release ventilation on gas exchange in patients with acute lung injury [J]. Acta anaesthesiologica Scandinavica, 2003, 47(5): 516-24.

[7] MAXWELL R A, GREEN J M, WALDROP J, et al. A randomized prospective trial of airway pressure release ventilation and low tidal volume ventilation in adult trauma patients with acute respiratory failure [J]. The Journal of trauma, 2010, 69(3): 501-10; discussion 11.

[8] ZHOU Y, JIN X, LV Y, et al. Early application of airway pressure release ventilation may reduce the duration of mechanical ventilation in acute respiratory distress syndrome [J].Intensive Care Med, 2017, 43(11): 1648-59.

[9] VARPULA T, VALTA P, NIEMI R, et al. Airway pressure release ventilation as a primary ventilatory mode in acute respiratory distress syndrome [J]. Acta anaesthesiologica Scandinavica, 2004, 48(6): 722-31.

[10] Ota.K, Tanigawa.K, Otani.T, et al. Does airway pressure release ventilation offer benefits over conventional ventilatory supports for severe acute respiratory distress syndrome?Critical Care Medicine.2009;37(12):A190.

[11] ANDREWS P, HABASHI N. Airway pressure release ventilation [J]. Current problems in surgery, 2013, 50(10): 462-70.

[12] EMR B, GATTO L A, ROY S, et al. Airway pressure release ventilation prevents ventilator-induced lung injury in normal lungs [J]. JAMA surgery, 2013, 148(11): 1005-12.

[13] ROY S, SADOWITZ B, ANDREWS P, et al. Early stabilizing alveolar ventilation prevents acute respiratory distress syndrome: a novel timingbased ventilatory intervention to avert lung injury [J]. The journal of trauma and acute care surgery, 2012, 73(2): 391-400.

[14] YOSHIDA T, RINKA H, KAJI A, et al. The impact of spontaneous ventilation on distribution of lung aeration in patients with acute respiratory distress syndrome: airway pressure release ventilation versus pressure support ventilation [J]. Anesthesia and analgesia, 2009, 109(6): 1892900 .

[15] HIRANI A, MARIK P E, PLANTE L A. Airway pressure-release ventilation in pregnant patients with acute respiratory distress syndrome: a novel strategy [J]. Respiratory care, 2009, 54(10): 1405-8.

[16]Kapian LJ ,BaiieyH ,FormosaV. Airway pressure reieaseventiiation increasescariacperformancein patients with acute unginjury/aduit respiratorydistresssyndrome.CritCare ,2001,5:221-226.

[17]HeringR,Boiten JC ,KreyerS,et al.Spontaneousbreathingduringairwaypressurereieaseventiiation in experimentaiiunginjury :effectson hepaticbiood fiow.IntesiveCareMed,2008,34:523-527.

[18]Kamath SS,SuperDM,MhannaMJ.effectsofairwaypressurereiease ventiiation on biood pressureand urineoutputin chiidren.PediatrPuimonoi ,2010,45:48-54.

[19] HABASHI N M. Other approaches to open-lung ventilation: airway pressure release ventilation [J]. Critical care medicine, 2005, 33(3 Suppl): S228-40.

[20] DAOUD E G, FARAG H L, CHATBURN R L. Airway pressure release ventilation: what do we know? [J]. Respiratory care, $2012,57(2)$ : 282-92.

[21] CAZA T, LANDAS S. Functional and Phenotypic Plasticity of CD4(+) T Cell Subsets [J]. BioMed research international, $2015,2015(521957$.

[22] BAJAJ A, RATHOR P, KABAK B, et al. Efficacy of Airway Pressure Release Ventilation in Critically III Patients: A Meta-Analysis of Randomized Controlled Trials, F].

[23] ANDREWS P L, SHIBER J R, JARUGA-KILLEEN E, et al. Early application of airway pressure release ventilation may reduce mortality in highrisk trauma patients: a systematic review of observational trauma ARDS literature [J]. The journal of trauma and acute care surgery, 2013, 75(4): 635-41.

[24] JAIN S V, KOLLISCH-SINGULE M, SADOWITZ B, et al. The 30-year evolution of airway pressure release ventilation (APRV) [J]. Intensive care medicine experimental, 2016, 4(1): 11.

\section{Tables}

Table 1: The basic information of the studies 


\begin{tabular}{|c|c|c|c|c|c|c|c|}
\hline \multicolumn{2}{|c|}{ Outcomes } & $\begin{array}{l}\mathrm{PaO}_{2} / \mathrm{FiO}_{2}, 28 \text {-day } \\
\text { mortality,MAP,Ppeak }\end{array}$ & $\begin{array}{l}\mathrm{PaO}_{2} / \mathrm{FiO}_{2}, 28 \text {-day } \\
\text { mortality,MAP,Ppeak }\end{array}$ & $\begin{array}{l}\mathrm{PaO}_{2} / \mathrm{FiO}_{2}, 28- \\
\text { day } \\
\text { mortality,MAP }\end{array}$ & $\begin{array}{l}\text { 28-day } \\
\text { mortality }\end{array}$ & $\begin{array}{l}\mathrm{PaO}_{2} / \mathrm{FiO}_{2}, 28- \\
\text { day mortality }\end{array}$ & $\mathrm{PaO}_{2} / \mathrm{FiO}_{2}, \mathrm{MAP}$, Ppeak \\
\hline \multicolumn{2}{|c|}{ Country } & China & China & Finland & Finland & USA & China \\
\hline \multirow[t]{2}{*}{ Age } & $\begin{array}{l}\text { Control } \\
\text { group }\end{array}$ & $52.0 \pm 15.1$ & $53.6 \pm 9.5$ & $\begin{array}{l}44.0(35.5- \\
53.0)\end{array}$ & $\begin{array}{l}46.5(37.2- \\
55.3)\end{array}$ & NA & $73(53,80)$ \\
\hline & $\begin{array}{l}\text { APRV } \\
\text { GROUP }\end{array}$ & $51.5 \pm 15.0$ & $54.3 \pm 8.4$ & $\begin{array}{l}50.0(38.5- \\
60.5)\end{array}$ & $\begin{array}{l}50.0(37.0- \\
60.0)\end{array}$ & NA & $63(40,73)$ \\
\hline \multicolumn{2}{|c|}{$\begin{array}{l}\text { Male and } \\
\text { female ratios }\end{array}$} & $91 / 47$ & NA & $39 / 19$ & $25 / 8$ & NA & $13 / 9$ \\
\hline \multicolumn{2}{|c|}{ Sample size } & 138 & 52 & 58 & 33 & 57 & 22 \\
\hline \multicolumn{2}{|c|}{$\begin{array}{l}\text { Intervention } \\
\text { measures }\end{array}$} & APRV+LTV & $A P R V+S I M V$ & $A P R V+S I M V$ & $\begin{array}{l}\text { APRV+SIMV- } \\
\text { PC/PS }\end{array}$ & $A P R V+S I M V$ & $A P R V+S I M V$ \\
\hline \multicolumn{2}{|c|}{$\begin{array}{l}\text { Studies } \\
\text { included }\end{array}$} & Zhou Y 2017 & J.-Q.LI 2016 & $\begin{array}{l}\text { T.VARPULA } \\
2004\end{array}$ & $\begin{array}{l}\text { T.VARPULA } \\
2003\end{array}$ & Ota, K 2009 & Song S 2016 \\
\hline
\end{tabular}

Table 2: The detailed information of the studies 


\begin{tabular}{|c|c|c|c|c|c|c|c|}
\hline \multirow[t]{2}{*}{ Lung injury score } & $\begin{array}{l}\text { Control } \\
\text { group }\end{array}$ & NA & $3.2 \pm 0.5$ & $3.1(2.7-3.3)$ & NA & NA & $1.80 \pm 0.85$ \\
\hline & $\begin{array}{l}\text { APRV } \\
\text { group }\end{array}$ & NA & $3.3 \pm 0.5$ & $3.0(2.6-3.5)$ & NA & NA & $2.02 \pm 1.09$ \\
\hline \multirow[t]{2}{*}{ Pmean } & $\begin{array}{l}\text { Control } \\
\text { group }\end{array}$ & $17.4 \pm 3.5$ & $22.7 \pm 3.6$ & NA & NA & NA & $15.67 \pm 2.64$ \\
\hline & $\begin{array}{l}\text { APRV } \\
\text { group }\end{array}$ & $18.3 \pm 3.9$ & $22.5 \pm 3.3$ & NA & NA & NA & $18.00 \pm 6.10$ \\
\hline \multirow[t]{2}{*}{ Ppeak $\left(\mathrm{cmH}_{2} \mathrm{O}\right)$} & $\begin{array}{l}\text { Control } \\
\text { group }\end{array}$ & $30.4 \pm 4.0$ & $29.5 \pm 6.9$ & NA & NA & NA & $24.42 \pm 5.45$ \\
\hline & $\begin{array}{l}\text { APRV } \\
\text { group }\end{array}$ & $31.7 \pm 4.5$ & $30.7 \pm 5.4$ & NA & NA & NA & $26.40 \pm 6.98$ \\
\hline \multirow[t]{2}{*}{$\mathrm{PaO}_{2} / \mathrm{FiO}_{2}(\mathrm{mmHg})$} & $\begin{array}{l}\text { Control } \\
\text { group }\end{array}$ & $138.3 \pm 56.1$ & $118 \pm 36$ & $165.01 \pm 9.75$ & $123(100-1500)$ & $96.9 \pm 26.2$ & $173.83 \pm 40.49$ \\
\hline & $\begin{array}{l}\text { APRV } \\
\text { group }\end{array}$ & $121.7 \pm 46.8$ & $119 \pm 35$ & $150.01 \pm 11.25$ & 137(135-173) & $99.7 \pm 27.1$ & $171.30 \pm 65.60$ \\
\hline \multirow[t]{2}{*}{ APACHEII score } & $\begin{array}{l}\text { Control } \\
\text { group }\end{array}$ & $20.2 \pm 7.6$ & $17.7 \pm 6.7$ & $14(11.25-17.0)$ & $14.0(11.0-16.0)$ & NA & $21.33 \pm 4.52$ \\
\hline & $\begin{array}{l}\text { APRV } \\
\text { group }\end{array}$ & $22.0 \pm 7.9$ & $18.5 \pm 4.6$ & $15(12.5-18.0)$ & $14.0(13.0-17.3)$ & NA & $23.20 \pm 8.89$ \\
\hline Studies included & & $\begin{array}{l}\text { Zhou Y } \\
2017\end{array}$ & $\begin{array}{l}\text { J.-Q.LI } \\
2016\end{array}$ & $\begin{array}{l}\text { T.VARPULA } \\
2004\end{array}$ & $\begin{array}{l}\text { T.VARPULA } \\
2003\end{array}$ & $\begin{array}{l}\text { Ota, K } \\
2009\end{array}$ & Song S 2016 \\
\hline
\end{tabular}

Figures 


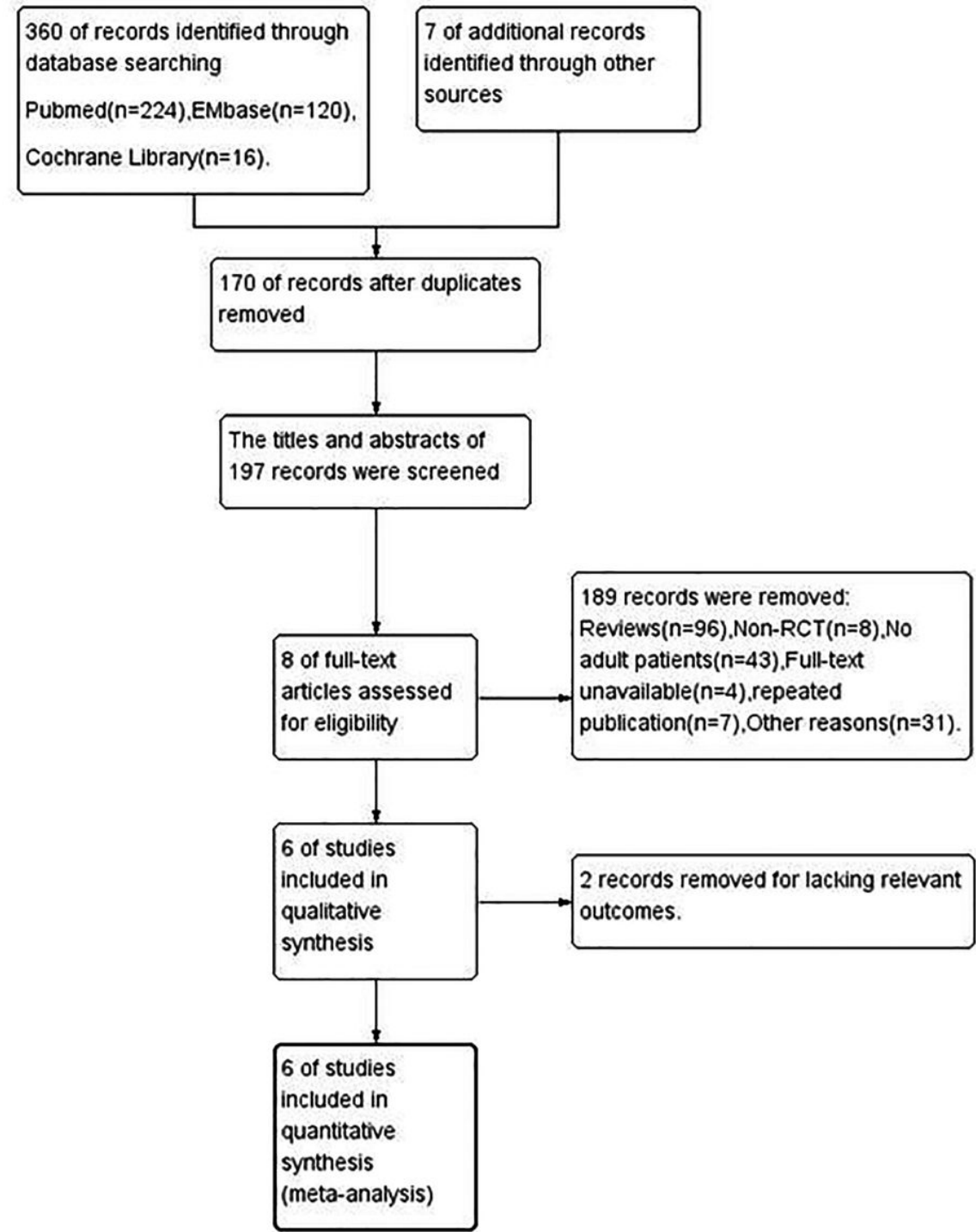

Figure 1

PRISMA flow diagram of the study selection process. 


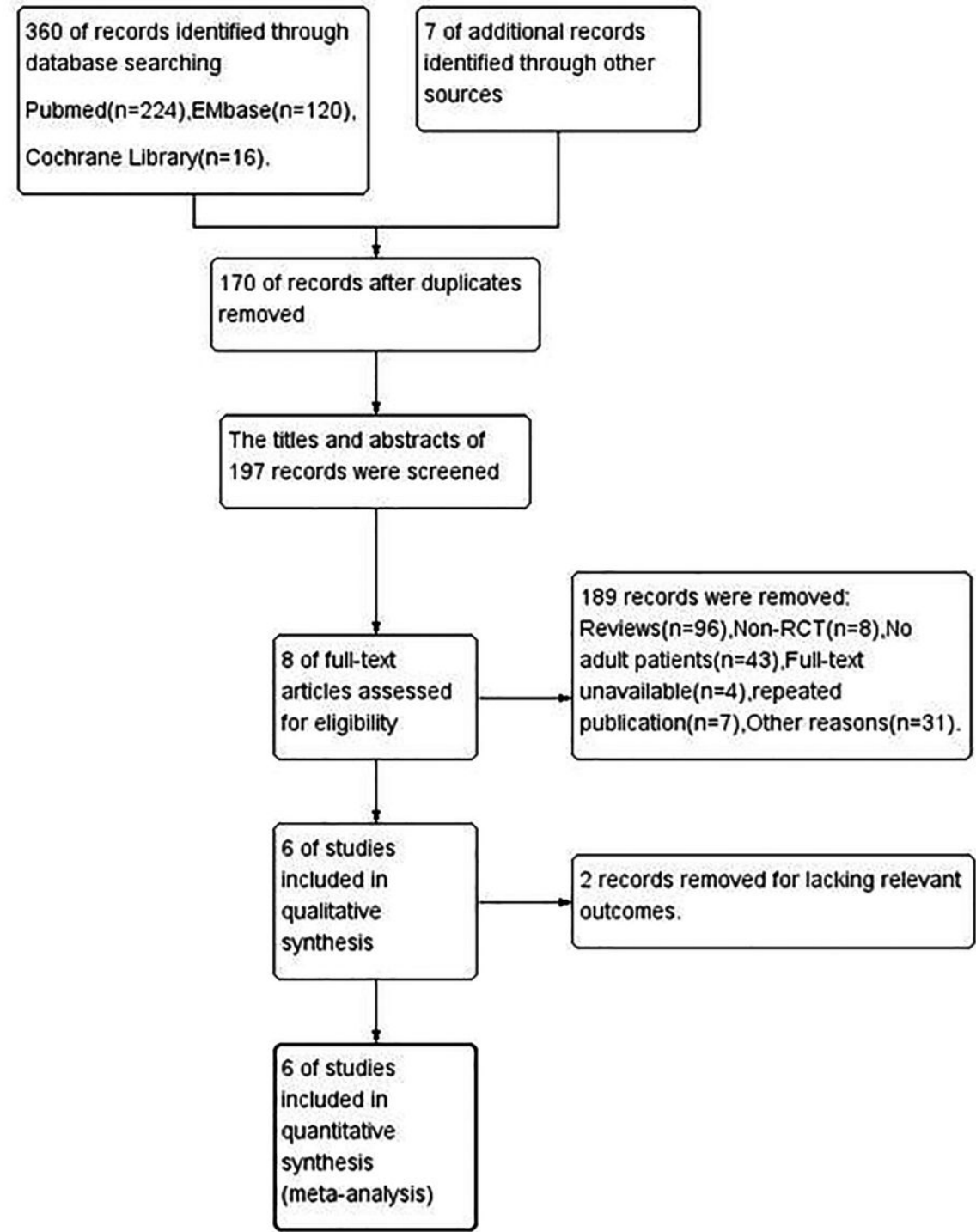

Figure 1

PRISMA flow diagram of the study selection process. 


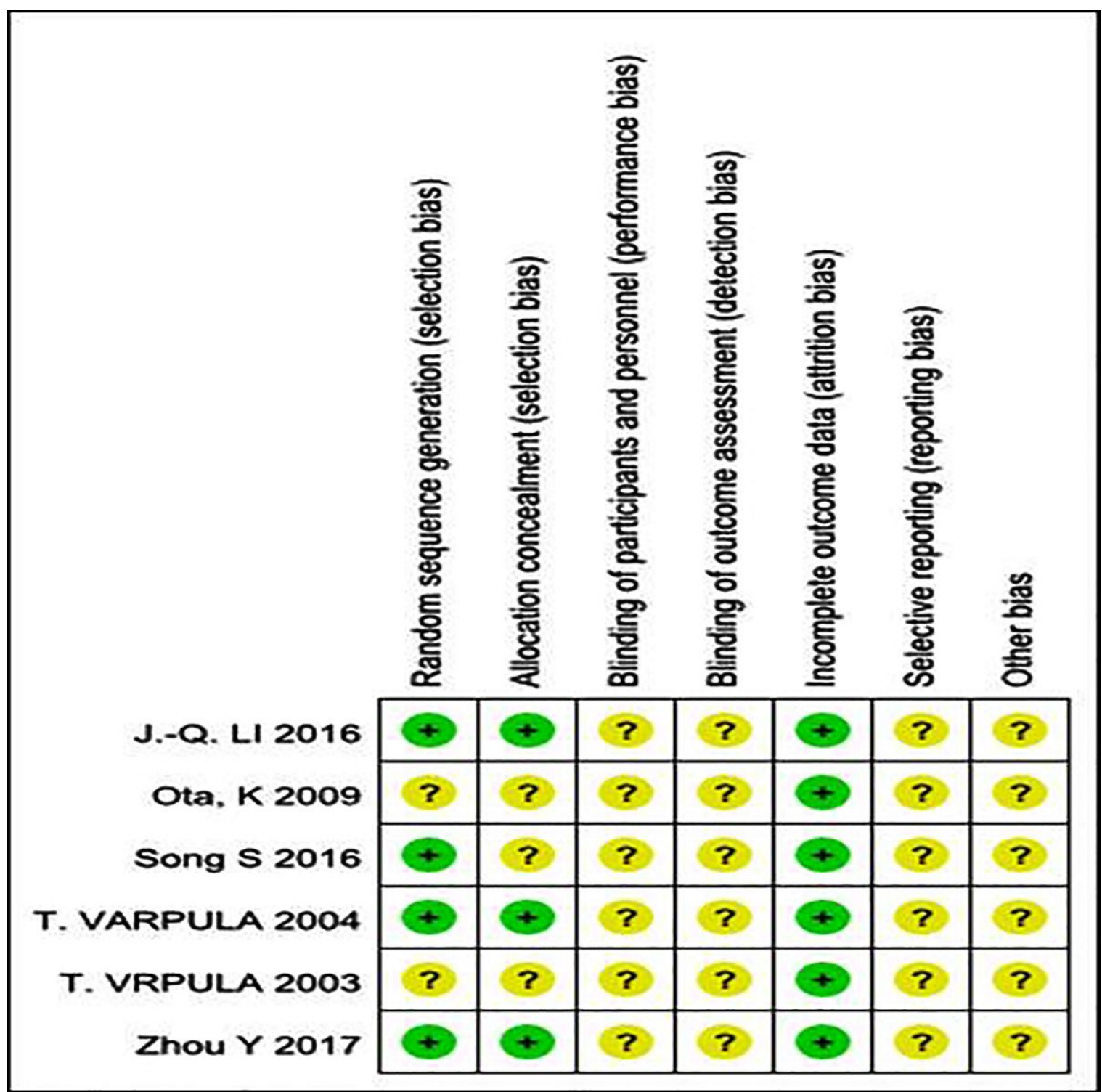

Figure 2

Results of methodological quality evaluation. All studies belonged to unclear risk of bias. 


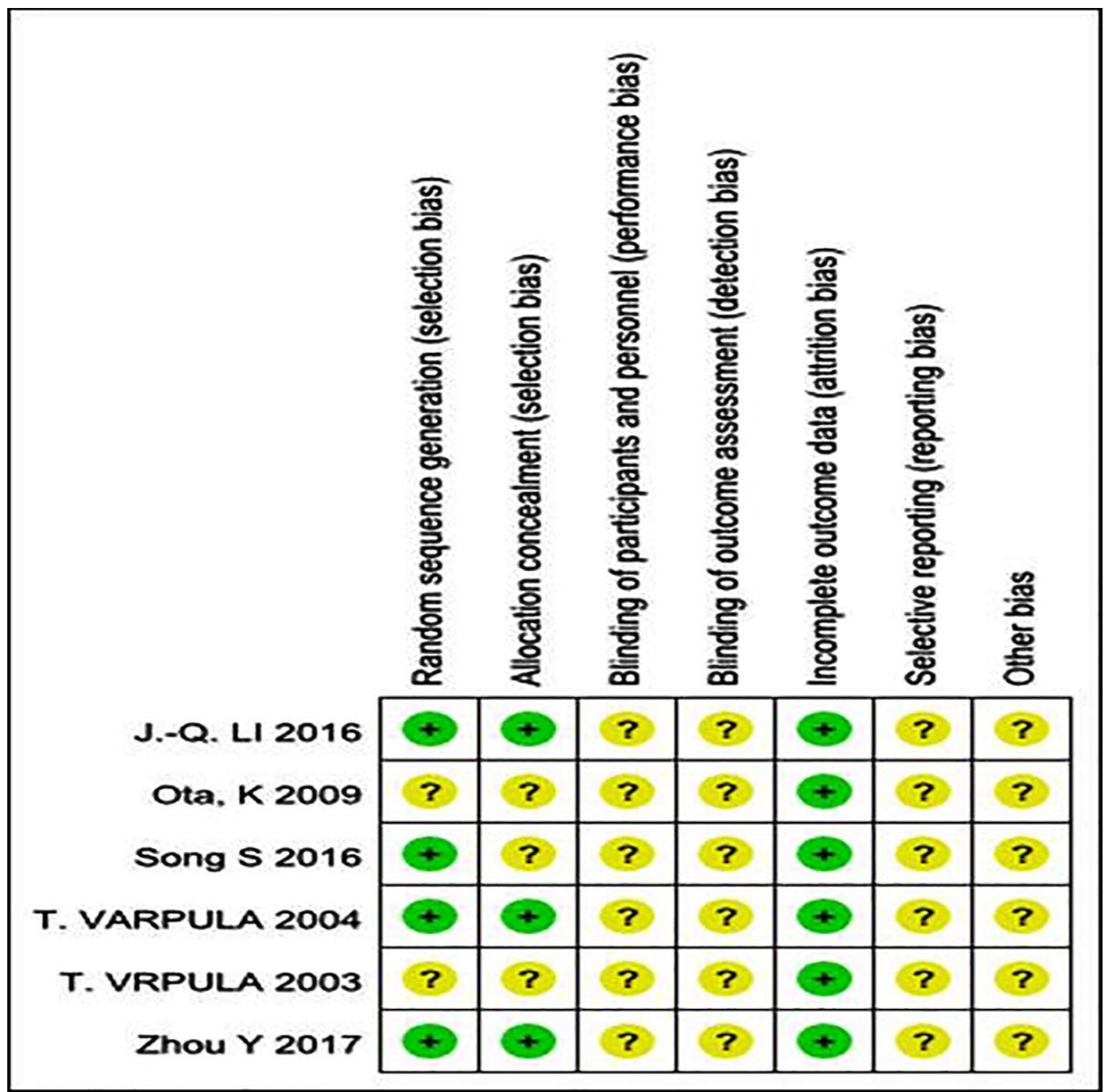

Figure 2

Results of methodological quality evaluation. All studies belonged to unclear risk of bias.

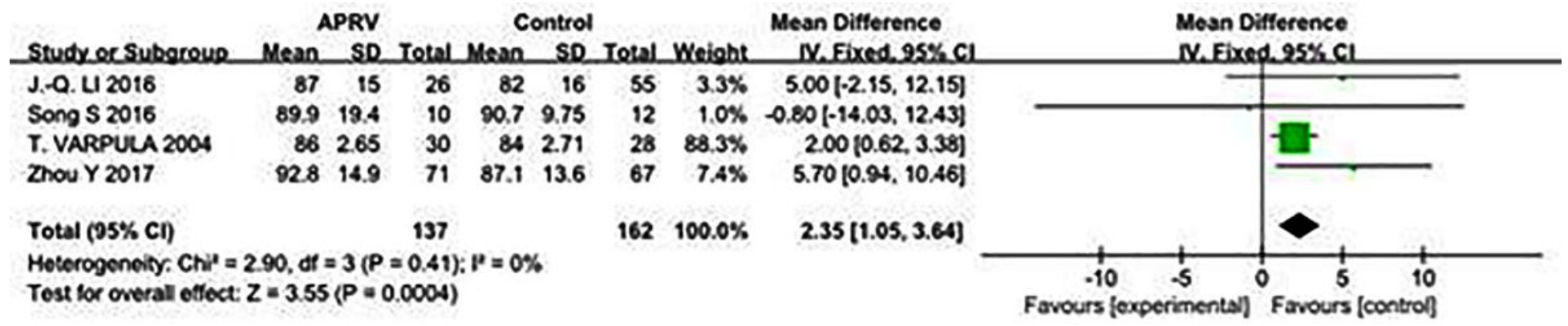

Figure 3

Forest plot comparing MAP among APRV group to that of control group. 


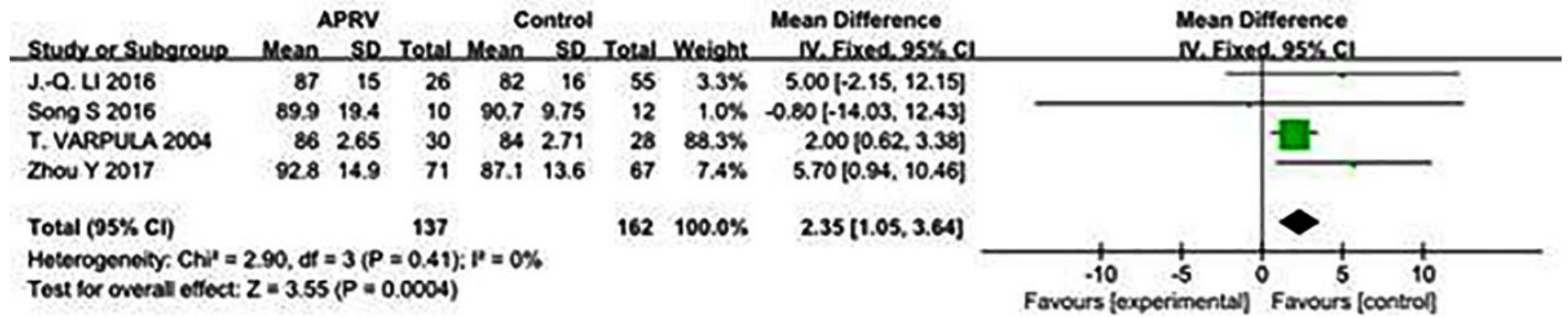

Figure 3

Forest plot comparing MAP among APRV group to that of control group.

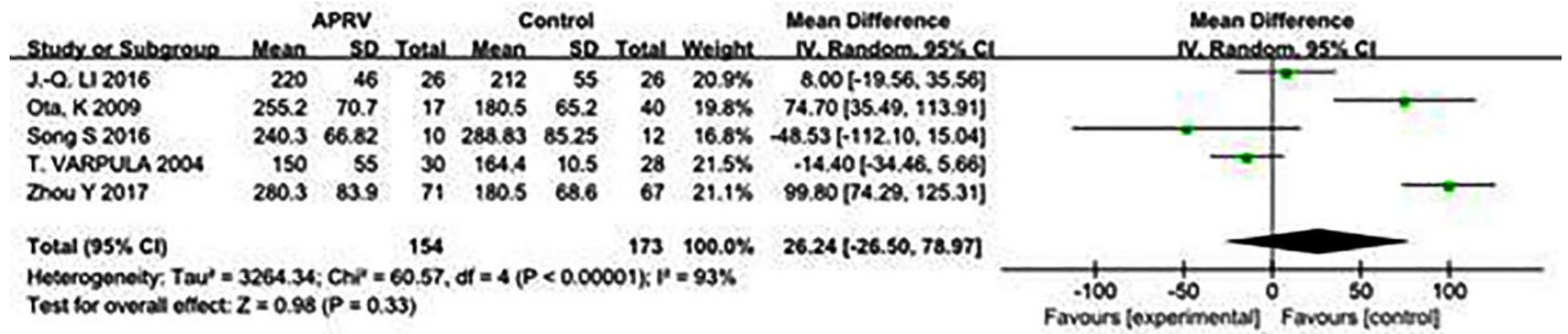

Figure 4

Forest plot comparing PaO2/FiO2 among APRV group to that of control group.

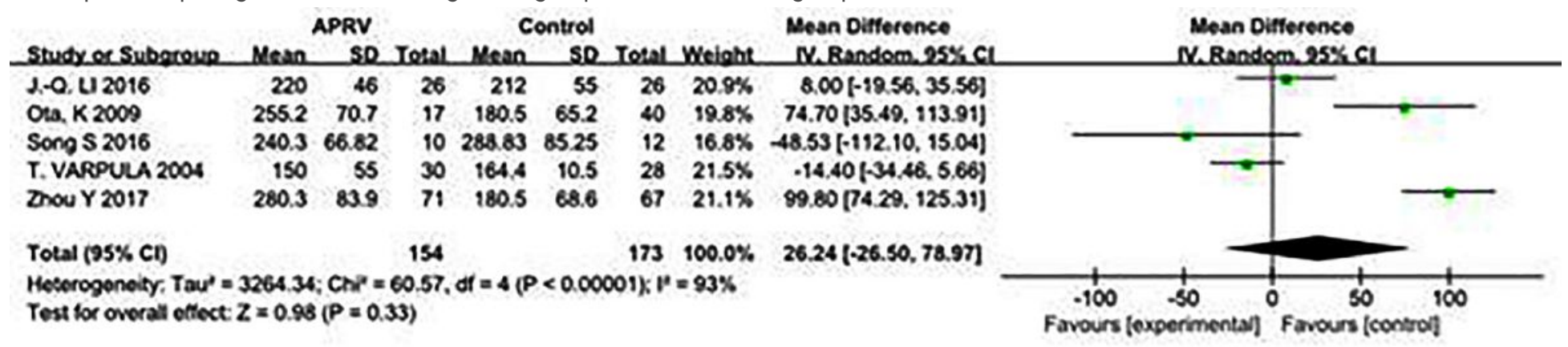

Figure 4

Forest plot comparing PaO2/FiO2 among APRV group to that of control group.

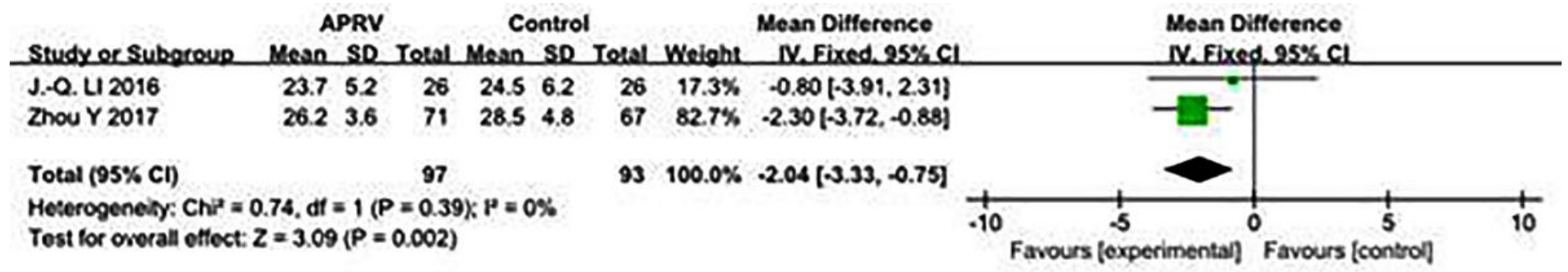

Figure 5

Forest plot comparing the Ppeak among APRV group to that of control group. 


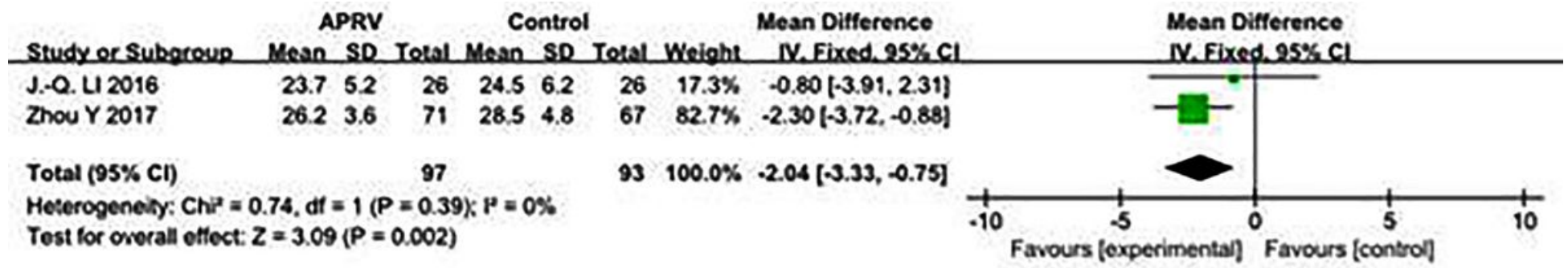

Figure 5

Forest plot comparing the Ppeak among APRV group to that of control group.

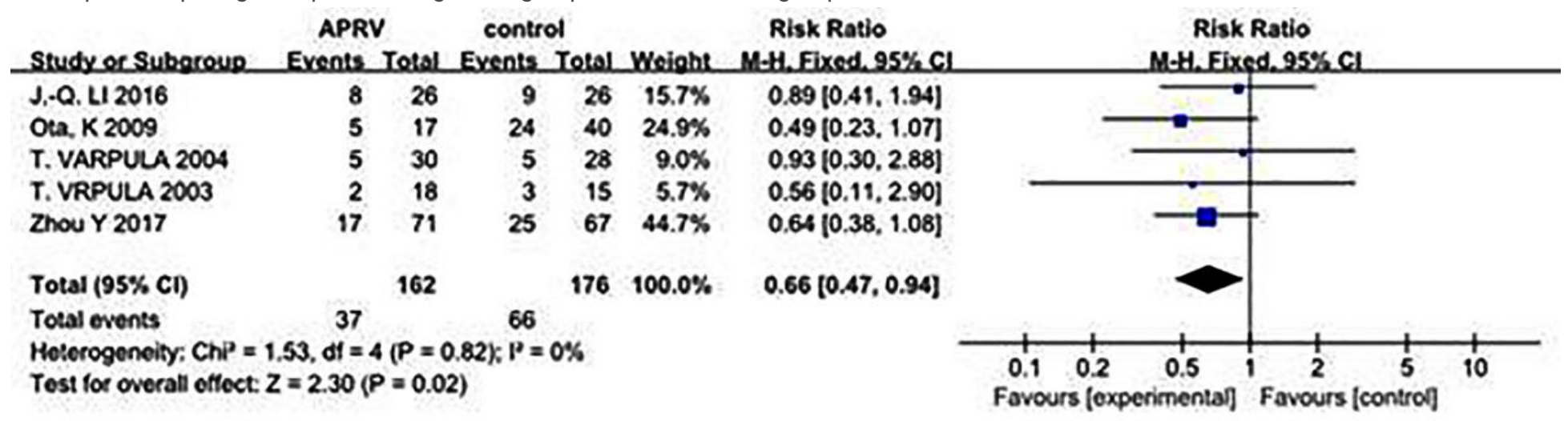

Figure 6

Forest plot comparing 28-day mortality among APRV group to that of control group.

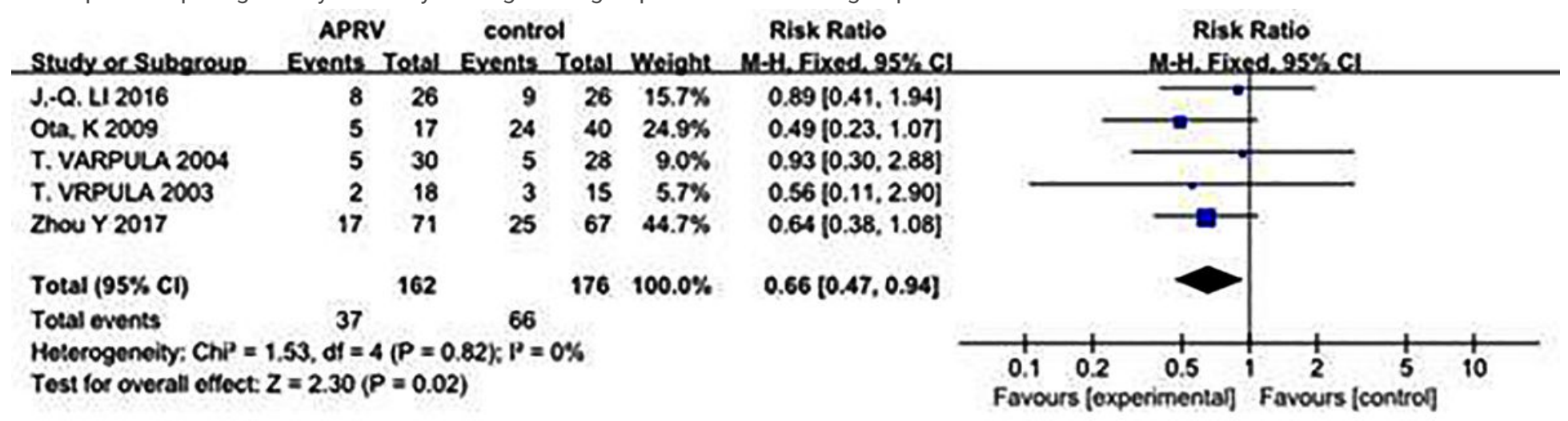

Figure 6

Forest plot comparing 28-day mortality among APRV group to that of control group. 


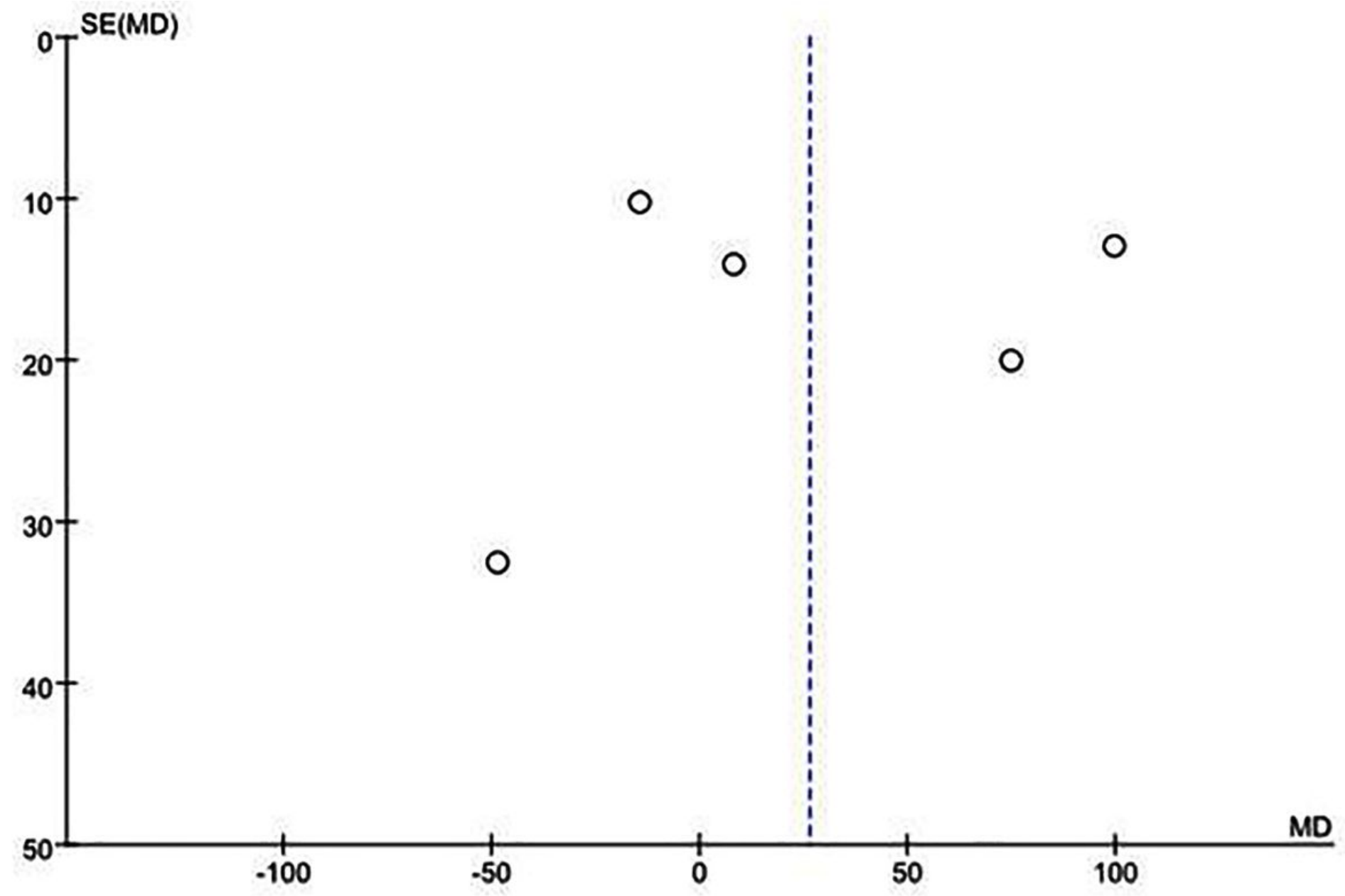

Figure 7

The funnel plot of the publication bias analysis, this funnel plot is not visually symmetric and reveals potential publication bias. RR: relative risk; SE: standard error. 


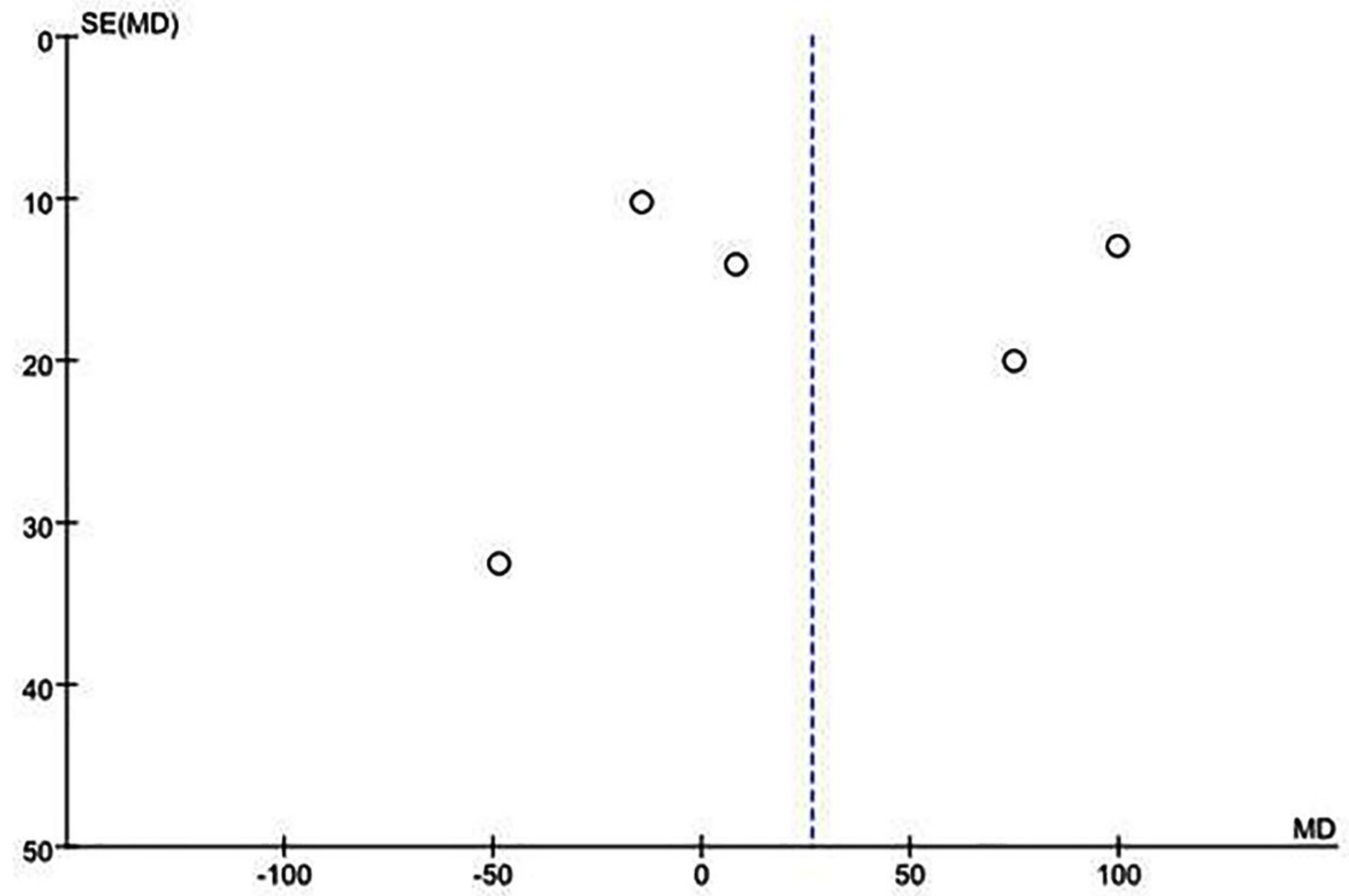

Figure 7

The funnel plot of the publication bias analysis, this funnel plot is not visually symmetric and reveals potential publication bias. RR: relative risk; SE: standard error.

\section{Supplementary Files}

This is a list of supplementary files associated with this preprint. Click to download.

- PRISMA2009ChecklistMSWord.doc

- PRISMA2009ChecklistMSWord.doc 